\title{
SWOT Analysis on Present Technical Education in India
}

\author{
H. Raja and S. Pathak
}

\section{ABSTRACT}

Education is the most important sector to be looked into in the process of building a powerful nation. The stakeholders of the education system parents, students, universities, industries and the governments have to work as a team to fulfill this objective. To our disappointment, on the other hand, the diminishing standards of institutions and the teaching learning process that are being practiced in most of the professional and other institutions especially in India have apparently caused calamity and severe damage to the culture and character of the country as such. The material covered in this Paper mainly deals with such problems, lacunae in the operational procedures adopted in imparting knowledge, feasible solutions to overcome such problems and a code book that might bring renaissance in the system when properly understood, accepted and implemented.

Keywords: Higher Education, ICT Tools, SWOT Analysis
Published Online: December 29, 2021

ISSN: $2736-4534$

DOI : 10.24018/ejedu.2021.2.6.183

H. Raja*

Associate Professor, Dr C V Raman

University Bilaspur, India.

(e-mail: hiralraja123@gmail.com

S. Pathak

Research Scholar, Dr C V Raman

University Bilaspur, India

(e-mail: sumati.gauraha@ gmail.com)

*Corresponding Author

\section{INTRODUCTION}

Academic experts in India had been constantly visiting a number of professional institutions and industries in India and different foreign countries for decades on some pretext or the other, collecting significant data for the purpose of study and documentation. The data collected so far by the experts have formed the basis for our SWOT analysis especially for our study on the present plight of professional education in India (Pathak et al., 2019; Pathak et al., 2020)

Based on our study, the following have been identified as the strengths and weaknesses of Indian education system and opportunities and threats faced (Pathak et al., 2019; Pathak et al., 2020).

Strengths

1. Strong interest among our youth to study Engineering.

2. Considerable admission capacity has been created by the private sector (Raja at el., 2020).

3. Increasing interest of Industry Associations (CII, FICCI, ASSOCHAM, and NASSCOM) and of Professional Societies to collaborate with academic institutions (Chandrakar et al., 2021).

4. The Accreditation initiatives of NBA and NAAC are serving to promote quality improvement in Engineering Education (Raja et al., 2021).

5. The TEQIP scheme funded by the World Bank provides the necessary resources for up gradation of about 100 institutions in the country (Sahu et al., 2021; Kumar et al., 2021).

Weaknesses

1. Engineering Education perceived only as a business opportunity by some (Diwan et al., 2016).
2. Severe shortage of qualified and competent faculty, especially in ICT (Tiwari et al., 2021).

3. While there are islands of excellence, these are rather few in number (Raja et al., 2020).

4. Lack of interest among graduating engineers and doctors for pursuing either research degree programs or teaching careers (Vishwakarma et al., 2020).

5. Lack of availability of (Genuine) PhDs for faculty positions.

6. Lack of adequate industry-institute interaction

7. Mismatch between education received by graduates and job requirements.

\section{OBSERVATIONS OF SWOT ANALYSIS}

The technical education in India is governed by the following stakeholders (i) Employees, (ii) Students, (iii) Employers, (iv) Society, (v) Alumni and (vi) Government. Figure 1 show as to how these stakeholders are connected to the system (Lenka et al., 2018; Raja et al., 2018).

\section{A. System Theoretic Approach to Study Present Day Technical Education in India}

In general, a 'system' is defined as the one which transforms an input or a set of inputs into an output or a set of outputs. Systems are categorized as (i) single input single output (SISO) systems, (ii) single input multi output (SIMO) systems, (iii) multi input single output (MISO) systems and (iv) multi input multi output (MIMO) systems. Fig. 1 shows an overview of the technical (professional) education system in India (Sinha, et al., 2011; Jain et al., 2020; Mahmod, 2020). 


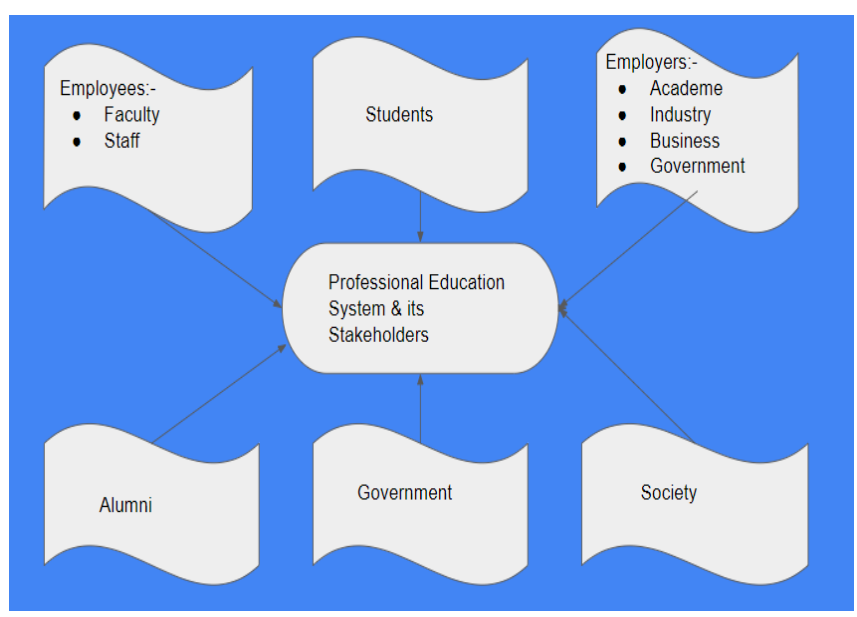

Fig. 1. Stakeholders of professional education system

Technical education system in India is treated here as a multi input multi output (MIMO) system with commitments from the stakeholders as inputs and value additions (i) Career livelihood, (ii) Prosperity livelihood, (iii) Tangible/intangible support, (iv) Competent workforce, (v) Industrial development and (vi) Societal development as outputs. The system parameters involve the following functionalities (i) Manpower development, education and training, (ii) Career development and employment, (iii) Interaction and communication, (iv) Research, development and consultancy, (v) Continuing education and (vi) Work skill development. Figure 2 shows the matrix of the model of the professional education system in India (Mahmood et al., 2020; Chandrakar et al., 2020; Tiwari et al., 2020).

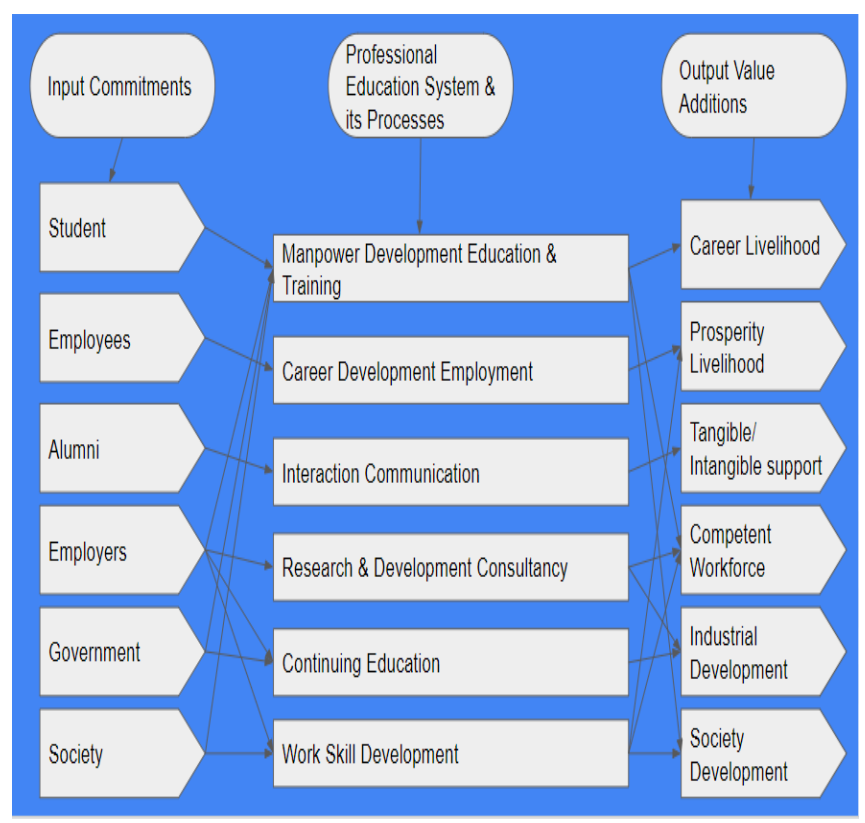

Fig. 2. Matrix of the professional education system model

It is but natural that stakeholders of any system would have expectations and requirements from the system, be it a business house or charitable trust. But are the means and methodologies by which these are currently being fulfilled justified? - A sincere self-introspection is required. Let us have a quick review of what kind of expectations and requirements that stakeholders of the professional education system practiced in India have. Figure 3 pictorially outlines the expectations and requirements of stakeholders (Raja et al., 2018; Raja et al., 2017).

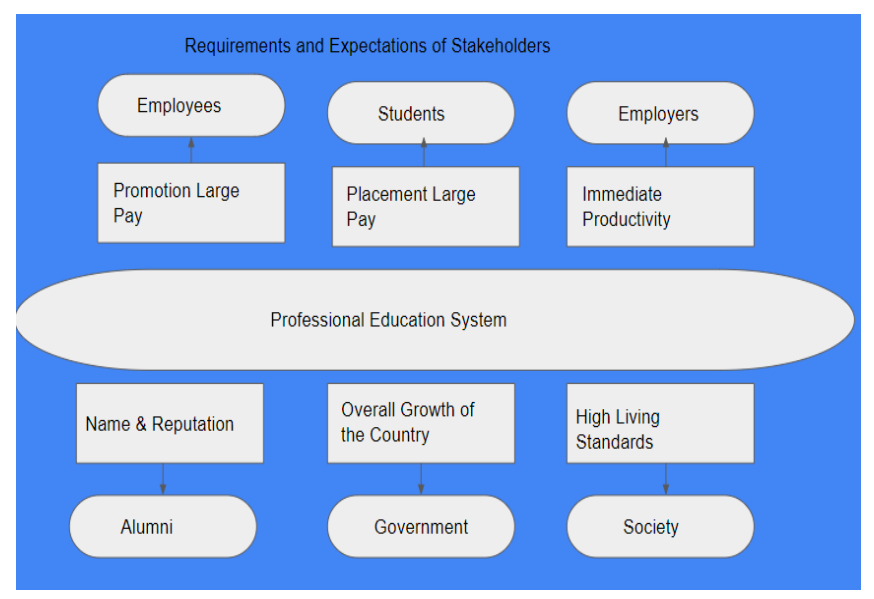

Fig. 3. Expectations and requirements of stakeholders

Most of the students join professional courses only with the expectation of getting good placement with a large pay package whether they deserve or not, though their expectations are quite justified (Chandrakar et al., 2021; Prithiviraj et al., 2017).

Most of the faculty members and staff have taken up to teaching profession only because of the fact that they could not get into highly and indiscriminately paid 'software jobs' (?!) and those teaching jobs are available aplenty; they expect promotion and frequent hike in salaries whether they deserve or not, though their expectations are quite justified (Raja et al., 2017; Khan et al., 2016)

Most of the alumni of an institution, especially of a private self-financing institution do not even say that they studied in that institution, and they prefer to identify themselves with the university to which the institution is affiliated; they expect the parent institution to gain global identity, name and reputation which they would love to share though their expectations are quite justified (Rawat et al., 2016).

Most of the promoters of professional institutions have two agenda while promoting institutions; one is an open agenda, that is, to give wide publicity with false claims in order to attract students in bulk and the other is a hidden agenda, that is, to make money and make more money, though their expectations are quite justified (Shukla et al., 2016; Raja et al., 2016; Diwan et al., 2016).

The stakeholders under the category 'Society' are (i) Parents and (ii) Industries; parents force their wards to go in for professional courses only with the expectation of sending their wards to foreign countries or to companies (preferably software companies) to earn a lot of money instantly and immediately; companies wish to hire students indiscriminately only with the requirement of head counting and filling bench positions, though their expectations are quite justified (Mate et al., 2016; Khan et al., 2016).

The government organizations (most of the officials in key positions) under the coveted expectations 'overall growth of the country and shining nation', sanction permission indiscriminately to less known or unknown, never the less, greedy people to start up any number of institutions with same name, of course, after a nice 
permutation and combination of their personal names and family names suffixed with least priority words like 'Institute', 'College' 'Research Centre' 'School', to name a few only, only for pecuniary and other benefits from the promoters (this fact has been brought out to light by media and apparently the governments are taking corrective steps to establish academic justice, let us hope so); though their expectations are quite justified. We wish to present here some of our observations as a revelation of the SWOT analysis. These observations are our opinions made on certain quantitative measures taken during the analysis (Diwan et al., 2016; Jain et al., 2020).

\section{B. Attitudes of $21^{\text {st }}$ Century Students, Teachers}

Institutions and Parents (a general opinion as observed by many senior academicians, professionals, administrators, policy makers who volunteered to participate in the analysis (names and affiliations are kept confidential) (Bhensle et al., 2014; Pandey et al., 2014)

\section{Attitude of Students}

- Learning is very easy, and it requires no effort.

- Access to information is very easy and so knowledge is acquired without any effort.

- Like instant food, one can have instant knowledge, instant skills, instant experience.

- Prosperity requires no hard work, sacrifice and experience and it is a DEMAND (Pandey et al., 2014).

D. Attitude of Teachers

- Knowledge is a commodity to be transacted.

- Knowledge acquisition is need based and not interest based (Pandey et al., 2014).

- Research is a waste, but promotion is a MUST.

\section{E. Attitude of Institutions}

- Institution is a trading joint, and education is a pure business (Dewangan et al., 2014).

- Students are customers and Teachers are SALESMEN.

- Institution is a factory wherein quantity is a slogan and quality is a jargon (Dewangan et al., 2014).

\section{F. Attitude of Parents}

- Wards should somehow get into the best (?) schools (good looking buildings and canteen).

- Wards should at any cost earn more marks (even if they read books one day before examination) (Jangde et al., 2014).

- Wards should necessarily get into highly paid jobs (even if they know nothing and do nothing) (Chouhan et al., 2014).

\section{TREND In ProfessionAl InSTITUTIONS - A BIRD's EyE VIEW}

The past, present and future trends among major stakeholders 'teachers' and students' of professional institutions, especially in India as observed by the analysts are briefly tabulated below (Tandan et al., 2013).
TABLE I: TEACHERS

\begin{tabular}{ccc}
\hline & TABLE I: TEACHERS & \\
\hline \hline Teachers of the & Present Day Teachers & Teachers of the \\
Past & Future \\
\hline Bosses & Guides on the Side & Fenior Students \\
Sages on the Stage & Preach Virtues & $?$ \\
Practiced Virtues & Pseudo Leaders & $?$ \\
Leaders & Knowledge Collectors & Knowledge \\
Knowledge & & Manipulators \\
Generators & $?$ & $? ?$ \\
Socially & & \\
Responsible & &
\end{tabular}

\begin{tabular}{ccc}
\multicolumn{3}{c}{ TABLE II: STUDENTS } \\
\hline \hline Students of the Past & Present Day & Students of the \\
& Students & Future \\
\hline Organized Learners & Self-Learners & Senior Students \\
& Passive & Selective \\
Interactive Listeners & Listeners & Learners \\
Practiced Virtues & $?$ & Self-Listeners \\
Leaders & Pseudo Leaders & $?$ \\
Knowledge Generators & Knowledge & $? ?$ \\
Socially Responsible & Collectors & $? ? ?$ \\
\hline \hline
\end{tabular}

\section{A. Warning}

This trend might lead to the following (Shukla et al., 2013):

- Lack of Interest and Stagnation in Knowledge Generation.

- Improper Use of Knowledge in every walk of life.

- Self-Centered pseudo-Knowledge Based Society (Shukla et al., 2013).

- Suppression of Knowledge and Intellectual Exploitation.

- Proliferation of Look-Busy-Do-Nothing (LBDN) Attitude.

- Threat to National Integrity due to Knowledge Divide (Tiwari et al., 2009).

- Compartmentalization, Individualization and Recession.

- Unemployment, Social Injustice and Organized Crimes.

- More committees, conferences to talk about these evils (Raja et al., 2015).

\section{B. How do we come out of this situation?}

The question that arises now is "Do we have a Basic Feasible Solution to overcome this problem?" Possibly 'YES' and possibly 'NO' - a paradoxical outlook is the only answer as on now. However, we shall look into the part of a Code Book developed by an NGO named Forum of Scientists Aiming Peace and Harmony (FOSAPAH) to resolve these kinds of problems (Diwan et al., 2015).

\section{THE CODE BooK}

Like 'Ten Commandments' this code book dictates certain 'dos' and 'don'ts' to the stakeholders 'students', 'teachers', 'institutions' and 'parents (Patel et al., 2012; Patel et al., 2012).

\section{A. For Students}

Dos

- Read while you read and play while you play

- Be clean, eat well, do physical exercises, dress well. 
- Be polite, respect every one, have civic sense, follow rules (Nagpure et al., 2012).

- Discuss concepts, attend classes regularly, write notes

- Use library and laboratories very well.

- Contact teachers, question them, discuss with them, confide in them.

- Ignite and kindle the FIRE in you to learn and learn more and more (Nagpure et al., 2012)

- Talk less, do more, behave yourself, present yourself, volunteer.

- Increase core competence, communication skills, ethical balance.

- Respect neighborhood, nature, ecology, fellow human beings.

- Understand, adapt, be silent and proactive, contribute and appreciate (Khan et al., 2015)

Don'ts (Raja et al., 2020; Kumar et al., 2020; Kumar et al., 2021)

- Do not postpone studies and writing assignments and records.

- Do not shout while talking anywhere in the campus or public places.

- Do not make ugly noises while eating and drinking (Raja et al., 2021).

- Do not litter on roads and inside buildings (Sinha et al., 2013).

- Do not drive fast (Speed thrills but it kills).

- Do not beg teachers for marks and irritate them (Sinha et al., 2015).

- Do not gossip and pass dirty comments on others.

- Do not misbehave in the class and cause embarrassment to others (Patra et al., 2018; Tiwari et al., 2020).

- Do not resort to malpractices in exams and cook up results in labs.

- Do not rag juniors and mislead fellow students (Ragging is a CRIME).

- Do not support mob mentality and take part in illegal activities (Raja et al., 2020).

- Do not steal books from library and components from labs.

\section{SUMMARY}

If the Dos and Don'ts of the Code Book are understood and practiced sincerely, the New Millennium Professional Education would turn out to be a multi-disciplinary, multimode, multi-media, multiple-partner enterprise. To be precise, the Professional Education System in India would turn out to be a Multiple Input Multiple Output (MIMO) Self Organizing System; else, it would turn out to be a SelfDestructive Chaotic System. Stakeholders! It is up to you to take it or leave it.

\section{CONFLICT OF INTEREST}

Authors declare that they do not have any conflict of interest.

\section{REFERENCES}

Bhensle, A.C. \& Raja, R. (2014). An efficient face recognition using PCA and Euclidean Distance classification, International Journal of Computer Science and Mobile Computing, 3(6), 407-413, ISSN: 2320-088X.

Bhensle, A.C. \& Raja, R. (2014). A survey on side-view based face recognition. International Journal for Scientific Research and Development, 2(4), 574- 577, ISSN: 2321-0613.

Chandrakar, R., Raja, R. \& Miri, R. (2021). Animal detection based on deep convolutional neural networks with genetic segmentation. Multimed Tools Appl. 73(2) 1-14, https://doi.org/10.1007/s11042-02111290-4.

Chandrakar, R., Raja, R., Miri, R. \& Tandan, S.R. (2020). Vehicle Detection on Sanctuaries Using Spatially Distributed Convolutional Neural Network. SAMRIDDHI: A Journal of Physical Sciences, Engineering and Technology. 12(1), 116-121, ISSN: 2229-7111.

Chandrakar, R., Raja, R., Miri, R., Patra,R.K. \& Sinha, U. (2021). Computer Succored Vaticination of Multi-Object Detection and Histogram Enhancement in Low Vision. Int. J. of Biometrics. Special Issue: Investigation of Robustness in Image Enhancement and Preprocessing Techniques for Biometrics and Computer Vision Applications, 34, 1-12.

Chandrakar, R., Raja, R., Miri, R., Sinha, U., Kushwaha, A.K. \& Raja, H. (2021). Enhanced The Moving Object Detection and Object TRACKING For Traffic Surveillance Using RBF-FDLNN AND CBF Algorithm. Expert Systems with Applications. 116306, ISSN: 09574174, https://doi.org 10.1016/j.eswa.2021.116306.

Chandrakar, R., Raja, R., Miri, R., Tandan, S.R., K. \& Laxmi, R. (2020). Detection and Identification of Animals in Wild Life Sancturies using Convolutional Neural Network, International Journal of Recent Technology and Engineering. 8(5), 23-45.

Chouhan, Y. \& Raja, R. (2013). Face Recognition With 3D Pose Estimation Using Gabor Wavelets. International Journal of Science, Engineering and Technology Research. 2(5), ISSN: 2278-7798.

Chouhan, Y. \& Raja, R. (2014). Robust Face Recognition and Pose Estimation System, International Journal of Science. Engineering and Technology Research, 3(1), ISSN: 2278-7798.

Dewangan, A.K., Raja, R. \& Singh, R. (2014) An Implementation of Multi Sensor Based Mobile Robot with Image Stitching Application. International Journal of Computer Science and Mobile Computing, 3(6), 603-609, ISSN: 2320-088X.

Dewangan, A.K., Raja, R. \& Singh, R. (2014). Multi Sensor and Multifunctional Robot with Image Mosaic. International Journal of Science, Engineering and Technology Research. 3(4), ISSN: 22787798.

Diwan, S.D., Thakur, A.K. \& Raja, H. (2016). Common Fixed Points of Four Mapping in Metric Spaces. International Journal of Science and Research. 5(5), May 2016, ISSN: 2089-2092.

Diwan, S.D., Thakur, A.K. \& Raja, H. (2006). Common fixed point theorems in metric spaces satisfying an implicit relation, Advance in Fixed Point Theory, 2, 167-174, 1927-6303.

Diwan, S.D., Thakur, A.K. \& Raja, H. (2015). Some Generalization on Fixed Point Theorems Related to Product of 3-Fuzzy Metric Spaces. Published in International Journal of Innovative Research in Science Engineering and Technology, 4(8), ISSN: 7571-7574.

Diwan, S.D., Thakur, A.K. \& Raja, H. (2016). Fixed point of Expansion Mapping Fuzzy Menger space with CLRs property. International Journal of Innovation in Science and Mathematics. 4(4), 143-145.

Diwan, S.D., Thakur, A.K. \& Raja, H. (2016) Some Generalization on Fixed Point Theorems Related to Different Types of Fuzzy Metric Spaces. Indian Journal of applied Research. 6(10), 635-644, ISSN: 2249-555X

Diwan, S.D., Thakur, A.K. \& Raja, H. (2016). Common fixed point theorem of Integral type in Menger probabilistic metric spaces. International Journal of applied Sciences and Mathematics. 3(4), 153156.

Jain, P., Jain, N. \& Raja, R. (2014). A Survey on Face Recognition in present Scenario. International Journal of Advanced Research in Computer Engineering and Technology. 3(2), 4206-4209, ISSN: 2278-1323.

Jain, S., Mahmood, Md. R., Raja, R., Laxmi, K.R., Gupta, A. (2020). Multi-Label Classification for Images with Labels for Image Annotation. SAMRIDDHI: A Journal of Physical Sciences, Engineering and Technology, 12, Special Issue (3), 183-188.

Jangde, K. \& Raja, R. (2013). Study of an Image Compression Based on Adaptive Direction Lifting Wavelet Transform Technique. International Journal of Advanced and Innovative Research 2(8), $25-$ 32, ISSN: 2278-7844. 
Jangde, K. \& Raja, R. (2014). Image Compression Based on Discrete Wavelet and Lifting Wavelet Transform Technique, International Journal of Science, Engineering and Technology Research. 3(3), 394399, ISSN: 2278-7798.

Khan, R. \& Raja, R. (2016). Neural Network Allied with Recognition of Facial Expressions of Basic Emotions. International Journal of Emerging Trends in Science and Technology. 2(11), 3311-3315, ISSN: 2348-9480.

Khan, R. \& Raja, R. (2016). Neural Network associated with recognition of Facial Expressions of Basic Emotions. Published in International Journal of Computer Trends and Technology. 3(4), 522-526, ISSN: 2231-2803.

Khan, R., Raja, R. (2016). Introducing L1- Sparse Representation Classification for facial expression. Published in Imperial Journal of Interdisciplinary Research (IJIR), 2(4), 115-122, ISSN: 2454-1362.

Kumar, S., Jain, A., Shukla, A. P., Singh, S., Raja, R. \& Rani, S. (2021). A Comparative Analysis of Machine Learning Algorithms for Detection of Organic and Nonorganic Cotton Diseases. Mathematical Problems in Engineering. Article ID 1790171, 18. https://doi.org/10.1155 /2021/1790171.

Kumar, S., Raja, R. \& Rohit kumar, K. (2021). Blockchain and Machine Learning Based Emerging Technology. Published by is an imprint of International Book Market Service Ltd. Brivibasgatve 197, LV-1039, Riga, Latvia, European Union. ISBN No: - 9786138945503.

Kumar, S., Raja, R., Tiwari, S, \& Rani, S. (2021). Cognitive Behavior \&amp; Human Computer Interaction based on Machine Learning Algorithm. Wiley \& Scrivener Publishing, ISBN No: 13:9781119791607.

Lenka, R.K., Rath, A.K., Tan, Z., Sharma, S. Puthal, D., Simha, N.V.R., Raja, R., Tripathi, S.S. \& Prasad, M. (2018). Building Scalable Cyber-Physical-Social Networking Infrastructure Using IoT and Low Power Sensors. IEEE Access 6(1), 30162-30173, ISSN: 2169-3536, 2169-3536, Digital Object 10.1109/ACCESS.2018.2842760.

Mahmood M, Mohan A, Raja R, Gupta A. (2021). Parametric Linear Subspace Method for Face Recognition and Pose Estimation. sms[Internet]. SAMRIDDHI: A Journal of Physical Sciences, Engineering and Technology, 12 (3), 210-220.

Mahmood, Md. R., Raja, R., Gupta, A., Jain, S. (2020). Implementation of Multi Sensor and Multi-Functional Mobile Robot for Image Mosaicking. SAMRIDDHI: A Journal of Physical Sciences, Engineering and Technology, 12 (3), 189-196.

Mate, P., Raja, R. \& Chouhan, Y. (2016). Face Recognition for Partial Occluded Image A survey, International Journal of Science. Engineering and Technology Research (IJSETR). 04(16), 3174-3181, ISSN: 2319-8885.

Mate, P., Raja, R. (2016). Adaptive Facial Detection \& Recognition Algorithm for Partially Occlude Images. International Journal for Research in Applied Science Technology (IJRASET). Paper ID IJRASET-2892, 3(6), ISSN: 2321-9653.

Nagpure, H, \& Raja, R. (2009). RBGCA-Bee Genetic Colony Algorithm for Travelling Salesman Problem. International Journal of Computer Science and Information Technologies. 3(6), 5384-5389, ISSN: 09759646.

Nagpure, H, \& Raja, R. (2012). The Applications Survey on Bee Colony Optimization. International Journal of Computer Science and Information Technologies. 3(5), 5137 - 5140, ISSN: 0975-9646.

Pandey, A.K., Raja, R. \& Chauhan, Y. (2014). Image Registration and its various forms: A Survey, International Journal of Science. Engineering and Technology Research. Vol. 3, Issue-4, pp. 11221128, ISSN: $2278-7798$.

Pandey, A.K., Raja, R. \& Chauhan, Y. (2014). Registration and Restoration from multiple degraded colour images. International Journal of Advanced Research in Computer Engineering \& Technology. 3, (11), ISSN: $2278-1323$.

Patel, R. K. \& Raja, R. (2009). A Differential Evolution algorithm for Nearest Node Selection in Peer to Peer Networks. International Journal of Computer Application. 5 (2), 108-116, ISSN: 2250-1797.

Patel, R.K. \& Raja, R. (2012). A survey on Nearest Node Selection using Different Evolution Algorithms. International journal of Advanced Research in Computer Science and Software Engineering. 2(8), August 2012, 467-471, ISSN: 2277-128X.

Pathak, S. Sahu, N., Raja, R., (2020). Application of ICT on student performance: an analysis based upon ORANGE and TANAGRA. National conference on Emerging Trends and Technologies in the area of I.T., Science, commerce and management SAICON-2020, NCSCCS- 021, ISBN: 978-81-937540-8-5.

Pathak, S., Bhatt, P., Raja, R. \& Sharma, V., (2020). Weka VS Rapid Miner: Models Comparison in Higher Education with these Two
Tools of Data, SAMRIDDHI: A Journal of Physical Sciences, Engineering and Technology. 12(3), 183-188.

Pathak, S., Raja, R., Sharma, V. \& Ambala, S. (2019). ICT Utilization and Improving Student Performance in Higher Education. International Journal of Recent Technology and Engineering. 8 (2), ISSN: 51205124.

Pathak, S., Raja, R., Sharma, V. \& K. Ramya Laxmi. (2020) A Framework of ICT Implementation on Higher Educational Institution with Data Mining Approach. European Journal of Engineering Research and Science. ISSN (Online): 2506-8016.

Pathak, S., Raja, R., Sharma, V., (2019). The Impact of ICT in Higher Education. Published in IJRECE. 7(1), 1650-1656, 2393-9028 (PRINT) ISSN: 2348-2281 (ONLINE) ISSN: 2393-9028 (PRINT) pp.

Patra R.K., Raja R. \& Sinha T.S. (2018) Extraction of Geometric and Prosodic Features from Human-Gait-Speech Data for Behavioral Pattern Detection: Part II. In: Bhattacharyya S., Chaki N., Konar D., Chakraborty U., Singh C. (eds) Advanced Computational and Communication Paradigms. Advances in Intelligent Systems and Computing. Vol 706. Springer, Singapore. ISBN 978-981-10-8236-8.

PrithviRaj, A., Raja, R., Akella, S. (2017). A New Framework for Trustworthiness of Cloud Services. International Journal of Research. 04(1). e-ISSN: 2348-6848, p-ISSN: 2348-795X.

Raja, H, Diwan, S.D. \& Thakur, A.K. (2015). Some Generalization on Fixed Point Theorems Related to Product of Fuzzy Metric Spaces. Published in International Journal of Innovative Research in Science Engineering and Technology, 4(8), ISSN: 6817-6820.

Raja, R. Sinha, T.S. \& Dubey, R.P. (2015). Biometrical Authentication of Twins from Side-View using Hybrid Approach. (BJSTH) Bharat Journal of Science Technology and Humanities, 1(1), 1-8, ISSN: 2454-6151.

Raja, R. Sinha, T.S. \& Dubey, R.P. (2017) Soft Computing and LGXP Techniques for Ear Authentication using Progressive Switching Pattern. Published in International Journal of Engineering and Future Technology. 2(2), 66-86, ISSN: 2455-6432.

Raja, R. Sinha, T.S. \& Dubey, R.P. (2017). Orientation Calculation of human Face Using Symbolic techniques and ANFIS. Published in International Journal of Engineering and Future Technology. 7(7), 37-50, ISSN: 2455-6432.

Raja, R. Sinha, T.S., Dubey, R.P. (2018). Recognition of human-face from side-view using progressive switching pattern and soft-computing technique. Association for the Advancement of Modelling and Simulation Techniques in Enterprises. Advance B, 58(N 1), 14-34, ISSN: 1240-4543.

Raja, R., Kumar, S., \& Rashid, M.D. (2020). Color Object Detection Based Image Retrieval using ROI Segmentation with Multi-Feature Method, in Wireless Personal Communication. Springer Journal, 1-24, https://doi.org/10.1 007/s11277-019-07021-6.

Raja, R., Agrawal, S. (2017). An Automated Monitoring System for Tourist/Safari Vehicles inside Sanctuary. Indian J. Sci. Res. 14 (2): 304-309, ISSN: 2250-0138 (Online).

Raja, R., Kumar, S, Choudhary, S. \& Dalmia, H. (2021). An Effective Contour Detection based Image Retrieval using Multi-Fusion Method and Neural Network, Submitted to Wireless Personal Communication, PREPRINT Version-2 available at Research Square DOI: 10.21203/rs.3.rs-458104/v1.

Raja, R., Kumar, S., RamyaLaxmi, K. \& Choudhary, S. (2021). Artificial Intelligence and Machine Learning in 2D/3D Medical Image Processing. In Taylor \& Francis Publishing House USA. ISBN $1000337138,9781000337136$.

Raja, R., Nagwanshi, K.K., Kumar, S. \& RamyaLaxmi, K. (2021). Data Mining Technologies using Machine Learning Algorithms. Published by, Wiley \& Scrivener, ISBN No: -13:9781119791782.

Raja, R., Patra, R.K., Sinha, T.S. (2017). Extraction of Features from Dummy face for improving Biometrical Authentication of Human. International Journal of Luminescence and Application. 7(3-4), Oct Dec 2017, Article 259, 507-512, ISSN: 2277-6362.

Raja, R., Raja, H., Patra, R. K., Mehta, K., Gupta, A. \& Ramya Laxmi, K. (2020). Assessment methods of Cognitive ability of human brains for inborn intelligence potential using Pattern Recognition. IntechOpen Biometric Systems ISBN 978-1-78984-188-6

Raja, R., Rashid, M.D., Patra, R. K. (2018). Study and Analysis of Different Pose Invariant for face Recognition under Lighting Condition. Sreyas International Journal of Scientists and Technocrats. 2(2), 11-17.

Raja, R., Sahu, N. \& Pathak, S. (2020). Teaching Learning Process Using ICT Tools Edited by Sandeep Kumar, Rohit Raja, Shrikant Tiwari, Shilpa Rani, "Cognitive Behavior \& Human Computer Interaction based on Machine Learning Algorithm", Wiley \& Scrivener Publishing in 2020. 
Raja, R., Sinha, T.S., Patra, R.K. \& Tiwari, S. (2018). Physiological Trait Based Biometrical Authentication of Human-Face Using LGXP and ANN Techniques (2018). Int. J. of Information and Computer Security. 10(2/3), 303-320.

Rawat, N., Raja, R. (2016). A Survey on Vehicle Tracking with Various Techniques. International Journal of Advanced Research in Computer Engineering and Technology (IJARCET). 5(2), 374-377, ISSN: 2278-1323.

Rawat, N., Raja, R. (2016). Moving Vehicle Detection and Tracking using Modified Mean Shift Method and Kalman Filter and Research. International Journal of New Technology and Research (IJNTR), 2(5), 96-100, ISSN: 2454-4116.

Sahu, A.K., Sharma, M., Tanveer, M., \& Raja, R. (2021). Internet of Things attack detection using hybrid Deep Learning Model, Computer Communications), 176. 146-154, 0140-3664, https://doi.org /10.1016 /j. comcom.2021.05.024

Shukla, R. \& Raja, R. (2013). Grid Based Multiple features based on image mosaicing, International Journal of Advanced Research in Computer Engineering and Technology. 2(2), 424-427, ISSN: 2231-2307.

Shukla, R., Raja, R. \& Thakur, S. (2013). Implementation of Grid-block based Image Mosaicing Approach and comparative Analysis with SIFT Approach. International Journal of Science. Engineering and Technology Research, 2(6), 1388-1393, ISSN: 2278-7798X.

Shukla, S., Raja, R. (2016). A Survey on Fusion on Color Images. International Journal of Advanced Research in Computer Engineering \& Technology (IJARCET), 5(6), 707-1709, 2278-1323.

Shukla, S., Raja, R. (2016). Digital Image Fusion using Adaptive NeuroFuzzy Inference System. International Journal of New Technology and Research (IJNTR), 2(5), 101-104, ISSN: 2454-4116.

Singh, S.K. \& Raja, R. (2014). Pagerank and link analysis using web mining. International journal of advance research in computer engineering and technology, 3(1), ISSN: 2278-1323.

Sinha, T.S., Chakraverty, D., Patra R. \& Raja, R. (2013) Modelling and Simulation for the Recognition of Physiological and Behavioural Traits Through Human Gait and Face Images. Discrte Wavelet Transforms- A Compendium of New Approaches and Resents Application. by intech China ISBN 978-953-51-0940-2, 95-125, Feb 2013, edited by Dr. Awad Kh. Al. Asmari http://dx.doi.org $110.5772 / 52565$

Sinha, T.S., Patra, R.K. \& Raja, R. (2011). A Comprehensive analysis of human gait for abnormal foot recognition using Neuro-Genetic approach. International Journal of Tomography and Statistics, Vol16(W11), 56-73, 2319-3339, http://ceser.res.in/ceserp/index.php/ijts.

Sinha, T.S., Patra, R.K., Raja, R. \& Dubey, R.P. (2015). ProgressiveRegressive Strategy for Biometrical Authentication. In the press to be published as a Book Chapter in a book entitled "Discrete Wavelet Transform by Intech Europe. ISBN 978-953-51-4356-7, 2015 edited by Dr. Dumitrum Baleanu.

Tandan, A. \& Raja, R. (2013). A Survey on Particle Swarm Optimization Methods for Image Segmentation. International Journal of Advanced Research in Computer Science and Software Engineering. Paper ID: V3I6-0620, 3(6), 1539-1544, ISSN: 2277-128X.

Tandan, A., Raja, R \& Chouhan,Y. (2014). Image Segmentation Based on Particle Swarm Optimization Technique, International Journal of Science, Engineering and Technology Research Paper ID: IJSETR2474, 3(1), 257-260, ISSN: 2278-7798.

Tiwari L., Raja R., Sharma V. \& Miri R. (2020). Fuzzy Inference System for Efficient Lung Cancer Detection. In: Gupta M., Konar D., Bhattacharyya S., Biswas S. (eds) Computer Vision and Machine Intelligence in Medical Image Analysis. Advances in Intelligent Systems and Computing, 992. Springer, Singapore. Online ISBN978981-13-8798-2

Tiwari, L., Raja, Awasthi, V. Miri, R., Sinha, G.R. \& Monagi H. Alkinani, Kemal Polat, (2021). Detection of lung nodule and cancer using novel Mask-3 FCM and TWEDLNN algorithms, Measurement. 172, 108882, ISSN: 0263-2241, https://doi.org/10.1016/j.measurement. 2020.108882.

Tiwari, L., Raja, R., Sharma, V., Miri, R. (2020). Adaptive Neuro Fuzzy Inference System Based Fusion of Medical Image. International Journal of Research in Electronics and Computer Engineering, 7(2), pp. 2086-2091, ISSN: 2393-9028 (PRINT) |ISSN: 2348-2281 (ONLINE)

Tiwari, R., Raja, R. Behar, B. \& Mehta, K. (2009). Concurrent Solution of SPMD Problem using MATLAB. Journal of Advanced Research in Computer Engineering. 3(2), 209-212, ISSN: 0974-4320

Vishwakarma, S.K., Sharma, P.C., Raja, R., Roy, V. \& Tomar, S. (2020). An Effective Cascaded Approach for EEG Artifacts Elimination. International Journal of Pharmaceutical Research. 12(4), ISSN 0975-2366, https://doi.org/10.31838/ijpr/2020. 12. 04.653.

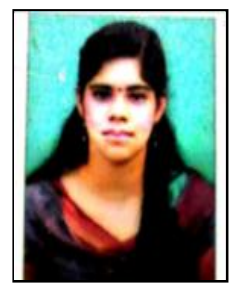

Sumati Pathak is pursuing Ph.D. in Information Technology \& Computer Application from Dr.C.V.Raman University in 2017-18. Her Main Research Interest in Image processing and Data mining she also wants to involve herself in the implementation of ICT tools in the fields of Education. Presently she is working as Assistance College Bilaspur (C.G.)

Professor in Information Technology \& Computer Application Department, Govt. Bilasa Girls Degree

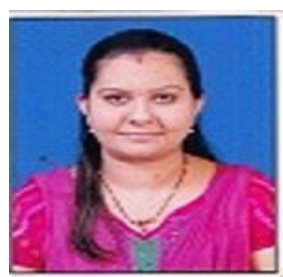

Dr. Hiral Raja is working as Associate Professor in the Mathematics Department at the Dr C V Raman University Bilaspur, has done her Ph.D. in Mathematics in 2017 from C. V. Raman University India. Her main research includes Image processing, embedded system, Artificial Intelligence and Sensor Signaling. She has granted successfully 2 patents. She has published approximately 10 research papers in national, international journals, (including Scopus, IEEE, and springer). 